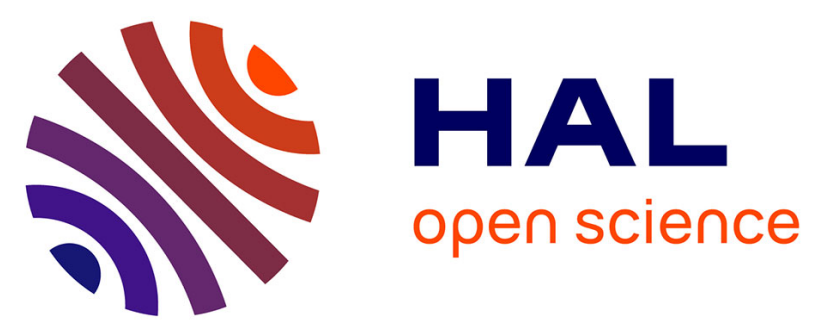

\title{
Comparative Studies Between Classical and Mutually Coupled Switched Reluctance Motors Using Thermal-Electromagnetic Analysis for Driving Cycles
}

Guangjin Li, Javier Ojeda, Emmanuel Hoang, Michel Lécrivain, Mohamed Gabsi

\section{To cite this version:}

Guangjin Li, Javier Ojeda, Emmanuel Hoang, Michel Lécrivain, Mohamed Gabsi. Comparative Studies Between Classical and Mutually Coupled Switched Reluctance Motors Using ThermalElectromagnetic Analysis for Driving Cycles. IEEE Transactions on Magnetics, 2011, 47 (4), pp.839847. 10.1109/TMAG.2011.2104968 . hal-00626706v2

\section{HAL Id: hal-00626706 \\ https://hal.science/hal-00626706v2}

Submitted on 4 Oct 2011

HAL is a multi-disciplinary open access archive for the deposit and dissemination of scientific research documents, whether they are published or not. The documents may come from teaching and research institutions in France or abroad, or from public or private research centers.
L'archive ouverte pluridisciplinaire HAL, est destinée au dépôt et à la diffusion de documents scientifiques de niveau recherche, publiés ou non, émanant des établissements d'enseignement et de recherche français ou étrangers, des laboratoires publics ou privés. 


\title{
Comparative Studies between Classical and Mutually Coupled Switched Reluctance Motors using Thermal- Electromagnetic Analysis for Driving Cycles
}

\author{
G.J. LI, Student Member, IEEE, J. OJEDA, Member, IEEE, E. HOANG, M. LECRIVAIN \\ M. GABSI, Member, IEEE
}

\begin{abstract}
This paper presents firstly copper and iron losses models of a classical Switched Reluctance Motor (SRM) and a Mutually Coupled Switched Reluctance Motor (MCSRM), the iron losses in different parts of machines are then detailed. Based on the power losses model, a Lumped Parameter (LP) transient thermal model during driving cycles is performed, the analytical results are validated by the Finite Element (FE) transient thermal model. Special attention has been paid to model the salient rotor and a method to transform the salient rotor into a nonsalient one has been proposed. A comparison between the maximum temperatures obtained by using different heat source (average power losses or instantaneous power losses during driving cycles) is given. The experimental tests are also realized to verify the analytical and numerical results.
\end{abstract}

Index Terms-Loss modeling, thermal analysis, thermal resistance network, switched reluctance motor (SRM), finiteelement method (FEM).

\section{INTRODUCTION}

$\mathrm{S}$ WITCHED Reluctance Motors (SRMs) have attracted increasing attention of electrical machine researchers due to their simplicity, robustness, low cost manufacture and low cost maintenance as well as high torque density [1]-[4]. All the active parts of the SRMs, e.g. the windings, are in the stator. This makes that the SRMs are considerably robust and can be applied in some harsh working environments, e.g. high speed, high ambient temperature and high pressure [5]-[9]. In contrast to the induction machines or permanent magnet machines, the SRMs can have a relatively simpler cooling system because it is often sufficient to cool the stator where exists all the copper losses and the most of the iron losses. However, for the induction machines or permanent magnets machines, the cooling of the rotor is often necessary to protect the rotor permanent magnets or the isolates of rotor induction windings. This is not easy to be performed because of the rotating rotor. Moreover, this increases certainly the cost of manufacture.

Besides the previous advantages of the SRMs, some of their drawbacks are also evident such as high acoustic noise and high vibration. In order to decrease the noise emission and the vibration, lots of studies have been performed and some efficient methods have been proposed such as optimizing the motor structure [10]-[12] or the control strategies [1]-[2], [13][14], using active materials as piezoelectric actuators [3], [15], etc. Another method as changing the stator winding distribution was studied in [16], the authors have proposed a new phase winding distribution as shown as in the Fig. 1 (b) (the three phases are wound as $\mathrm{A}+$ A-_B+_B-_C+_C-...) while the phase winding distribution of classical SRMs is shown in Fig. 1(a) (the three phases are wound as A+_A-_B-_B+_C+_C-...). In contrast to classical SRMs, in which the mutual flux as well as mutual inductances between phases are very low and often negligible (in Fig. 1 (a), the phase $\mathrm{A}$ is excited with constant current, there is nearly no flux of phase A that crosses through other phases, e.g. phase $\mathrm{B}$ and phase $\mathrm{C}$ ), the new winding distribution leads that the machine has mutual inductances between phases, which are negative while their absolute values are approximately one half of those of the phase self inductances. Due to the mutual inductances between phases, this kind of motors could be classed into the Mutually Coupled Switched Reluctance Motor (MCSRM) category as in [17], in which the notion of MCSRM is reported. The authors in [16] have also found that, when the phases are excited in rectangular waveform currents, due to mutual inductances, the levels of vibration and acoustic noise of the machine are dramatically reduced, and the converter circuit can be also simplified. Further studies are reported in [6]-[7], the comparison of different current waveforms has been carried out, when the three phases of the MCSRMs are excited in sinusoidal waveform currents, a strong torque augmentation has been observed at high current densities. Moreover, the MCSRMs are found much less sensitive to the magnetic saturation than classical SRMs.

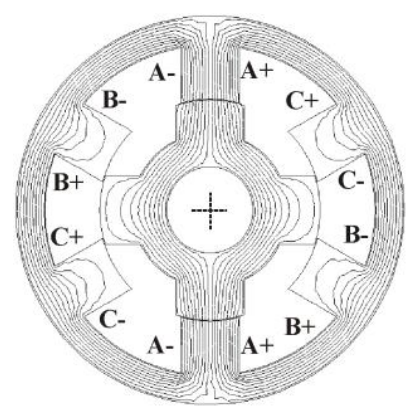

(a)

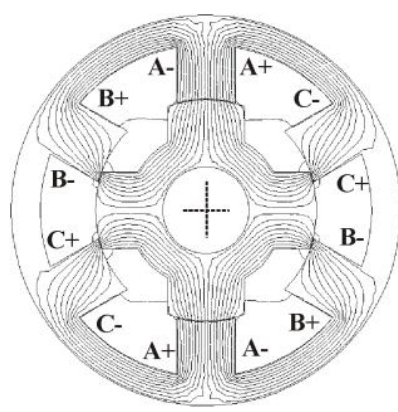

(b)
Fig. 1 Stator winding distributions of the classical SRM and MCSRM and flux lines with the phase A excited in constant current. (a) classical SRM, (b) MCSRM.

To our best knowledge, few studies about the comparison of power losses and thermal performances between the classical SRMs and MCSRMs have been performed in accessible literatures at present time. In this paper, the copper and iron 
losses of the classical SRM and the MCSRM have been computed for the same driving cycle, which is given in the machine specifications as shown as in the Fig. 2. The period of a driving cycle of these two machines is 6000 seconds. During one driving cycle, the maximum and minimum torques are respectively $7 \mathrm{Nm}$ and $0.5 \mathrm{Nm}$ (see the Fig. 2 (a)), while the maximum and minimum mechanical speeds are respectively $7500 \mathrm{tr} / \mathrm{min}$ and $100 \mathrm{tr} / \mathrm{min}$ (see the Fig. 2 (b)). The Lumped Parameter (LP) transient thermal model is realized, and the copper and iron losses are used as heat sources to predict the variation of temperatures at different parts of the machine during several driving cycles (after several driving cycles, the thermal regime of the machine could be permanent). The analytical results are also validated by the transient Finite Element Method (FEM) based on ANSYS transient thermal 2D.

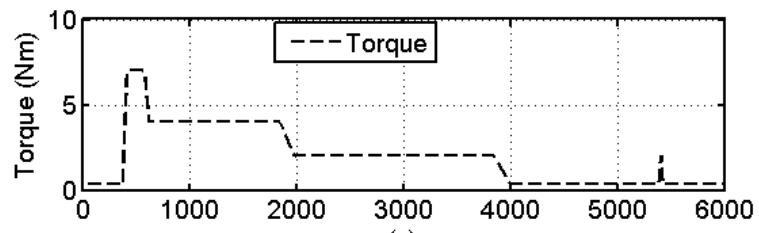

(a)

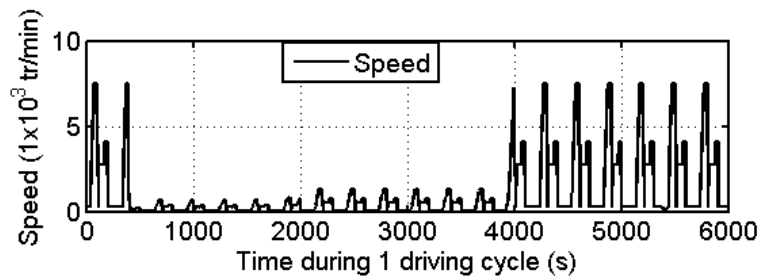

(b)

Fig. 2 Torque and mechanical speed versus time during one driving cycle (machine specification of the classical SRM and the MCSRM).

\section{COPPER AND IRON LOSSES MODEL OF SRMS}

\section{A. Copper Losses during one Driving Cycle}

Without rotor windings, the copper losses of the SRMs are primarily in stator windings, which can be computed as

$$
P_{j}=r J_{R M S}^{2} V_{c u}
$$

Where $r(\Omega \mathrm{m}), J_{R M S}\left(\mathrm{~A} / \mathrm{m}^{2}\right)$ and $V c u\left(\mathrm{~m}^{3}\right)$ are the copper resistivity (in this paper, $r$ is considered as independent of the temperature variation), the RMS current density and the total copper volume of three phase windings of SRMs, respectively. In order to calculate the copper losses during one driving cycle, the key difficulty is to obtain the RMS current density versus time during one driving cycle. Since the torque versus time during one driving cycle is already given as in the Fig. 2 (a), thus, it is sufficient to obtain the average torque versus RMS current density. This has been performed by the FEM $2 \mathrm{D}$, the three phases of the two machines are excited in sinusoidal waveform currents and the results are shown in the Fig. 3. Taking into account the magnetic saturation and using the Basic Fitting Method, the numerical relationship between the average torque and RMS current density can be then established as

$$
T_{a v}=K_{1} J_{R M S}+K_{2} J_{R M S}^{2}+\cdots+K_{n} J_{R M S}^{n}
$$

where $K_{1}, K_{2}, \ldots K_{n}$ are constants depending on the magnetic materials and the kind of machines. The copper losses during one driving cycle of the foregoing classical SRM and MCSRM are then obtained and shown in the Fig. 4. A significant difference between the maximum values of copper losses is observed. This is because that, in order to produce a maximum torque of $7 \mathrm{Nm}$, the classical SRM must have a RMS current density of $39 \mathrm{~A} / \mathrm{mm}^{2}$ while the MCSRM should only have a RMS current density of $15 \mathrm{~A} / \mathrm{mm}^{2}$. Thus, with the same copper resistivity and the same total copper volume (see Eq. 1), the maximum copper loss of the classical SRM is 6.8 times higher than that of the MCSRM.

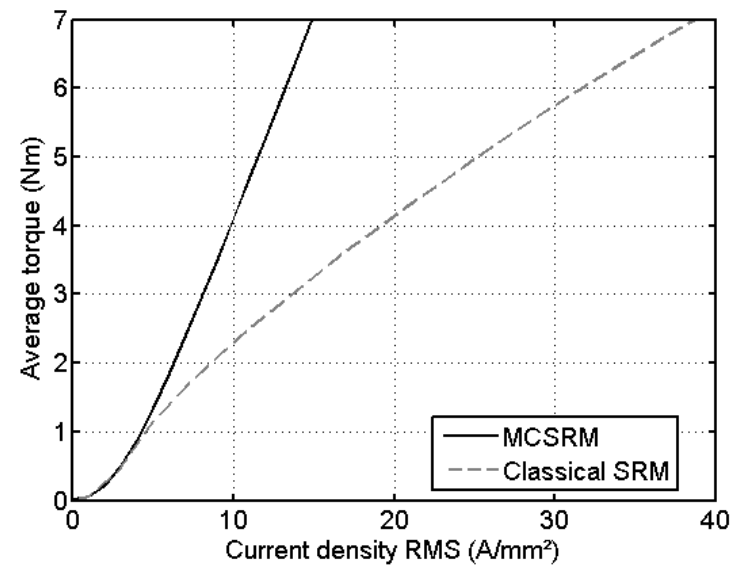

Fig. 3 Comparison of average torque versus current density RMS between the classical SRM and the MCSRM (three phases excited in sinusoidal waveform currents).

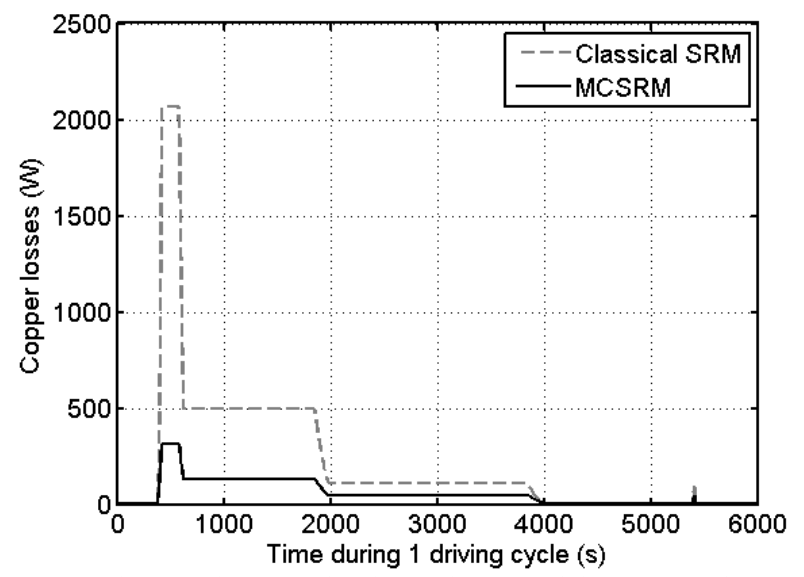

Fig. 4 Total copper losses of the classical SRM and the MCSRM during one driving cycle (three phases excited in sinusoidal waveform currents).

\section{B. Iron Losses during one Driving Cycle}

The iron losses in stator as well as in rotor, as one kind of heat source in the electrical machines, should be computed to predict precisely the temperatures of different parts of machines. In contrast to some of previous studies, in which the iron losses are often computed at certain driving points or with duty cycles, where the torques (corresponding to copper losses) and the mechanical speeds (corresponding to iron losses) are often fixed [18]-[27], the iron losses in this paper 
are instantaneous during one driving cycle. The stator and rotor iron losses densities $\left(P_{x}\left(\mathrm{~W} / \mathrm{m}^{3}\right)\right)$ could be obtained using the general expressions as follows

$$
\begin{aligned}
P_{x}\left(W / m^{3}\right)= & f_{x}\left(k_{h 1} \Delta B_{p p}+k_{h 2} \Delta B_{p p}^{2}\right) \\
& +k_{e} f_{x} \int_{0}^{\frac{1}{f_{x}}}\left(\frac{\partial B}{\partial t}\right)^{2} d t
\end{aligned}
$$

where

$f_{x}(x=R, S)$

$k_{h l}=5 \mathrm{~A} / \mathrm{m}$ and

$k_{h 2}=40 \mathrm{~A} / \mathrm{m}$

Rotor $(R)$ or Stator $(S)$ electrical frequency,

$B_{p p}($ Tesla $)$

$k_{e}=0.022 \mathrm{Am} / \mathrm{V}$

Hysteresis loss coefficients,

Peak-to-Peak value of flux density,

Eddy current loss coefficient.

In this paper, the hysteresis and eddy current loss coefficients are obtained by experimental methods, the variation of rotor and stator magnetic flux densities as well as their frequencies are computed by time-stepping Finite Element Method (FEM) 2D. In order to compute the stator and rotor iron losses versus time during one driving cycle, the relationship between the iron losses for unit speed $(1 \mathrm{rad} / \mathrm{s})$ and the RMS current density is firstly established, and with the expression Eq. 3, the numerical relationship between the iron losses for unit speed $(1 \mathrm{rad} / \mathrm{s})$ and the average torque could then be obtained, since torque and the mechanical speed are given in the machine specification as in Fig. 2, the instantaneous stator as well as rotor iron losses (sum of hysteresis and eddy current losses) can be finally calculated.

The results of rotor, stator and entire machine iron losses versus time during one driving cycles are shown in the Fig. 5 and in the Table 1. The maximum and average rotor, stator and total iron losses of the classical SRM are approximately 2 times higher than those of MCSRM.

During the procedure of calculating the rotor iron losses of these two machines, it is found that the rotor and the stator flux density frequencies $\left(f_{R}\right.$ and $\left.f_{S}\right)$ of the classical SRM as well as stator flux density $(B)$ frequency of the MCSRM are identical, while these foregoing frequencies are 2 times higher than the rotor flux density frequency of the MCSRM. Thus, as
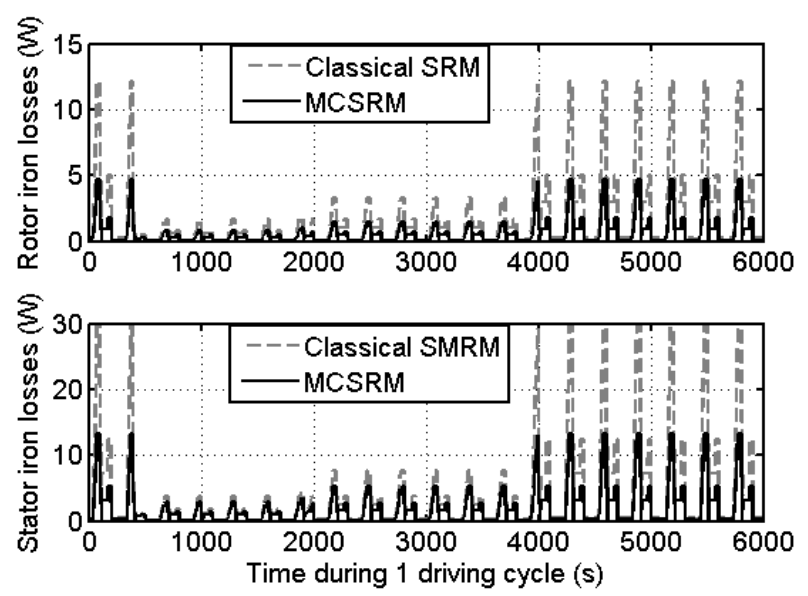

(a)

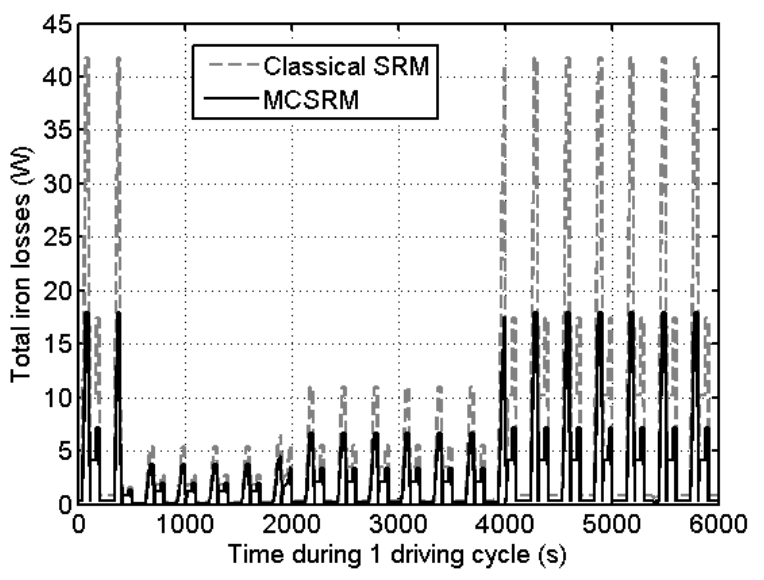

(b)

Fig. 5 Comparison of iron losses during one driving cycle between the classical SRM and the MCSRM. (a) rotor and stator iron losses, (b) total iron losses (sum of rotor and stator iron losses).

Table 1

Maximum and Average Rotor, Stator and Total Iron Losses during one Driving Cycle

Maximum rotor iron losses (W)

Average rotor iron losses (W)

Maximum stator iron losses (W)

Average stator iron losses (W)

Maximum total iron losses (W)

Average total iron losses (W)

\begin{tabular}{cc} 
Classical SRM & MCSRM \\
\hline 12 & 5 \\
1.6 & 0.6 \\
30 & 13 \\
3.8 & 1.9 \\
42 & 18 \\
5.4 & 2.5 \\
\hline
\end{tabular}

shown in expression Eq. 3, even if the amplitudes of rotor magnetic flux densities of these two machines are identical, the rotor hysteresis and eddy current losses of the classical SRM could be respectively 2 times and 4 times higher than those of the MCSRM. This makes the MCSRM a very outstanding candidate for the high speed applications, because the higher the mechanical speed, the lower the rotor iron losses of the MCSRM comparing to that of the classical SRM. When to the stator iron losses of these two machines, the harmonic analysis is performed. As mentioned in previous sections, the three phases are excited in sinusoidal waveform currents, and the harmonics of phase flux (phase A is chosen in this paper) versus RMS current density for these two machines are shown in the Fig. 6. It is found that the classical SRM has important third and fifth harmonics while the harmonics of the MCSRM are relatively low, since the fundamental frequencies of stator flux densities of these two machines are similar, the classical SRM could consequently have higher stator hysteresis as well as eddy current losses. Furthermore, as shown in Fig. 6, in contrast to the classical SRM, the phase flux harmonics of the MCSRM decrease with the increase of RMS current density. Thus, at high average torque and low mechanical speed, the stator iron losses of MCSRM due to harmonics could be significantly lower than that of classical SRM. 


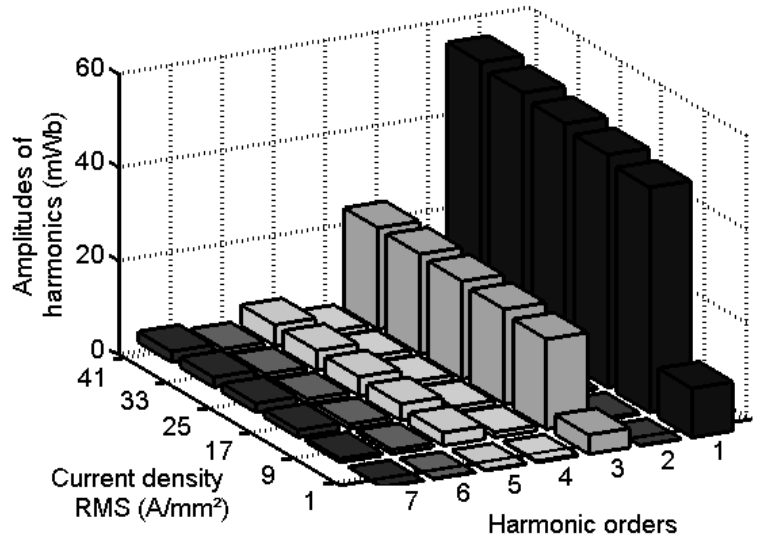

(a)

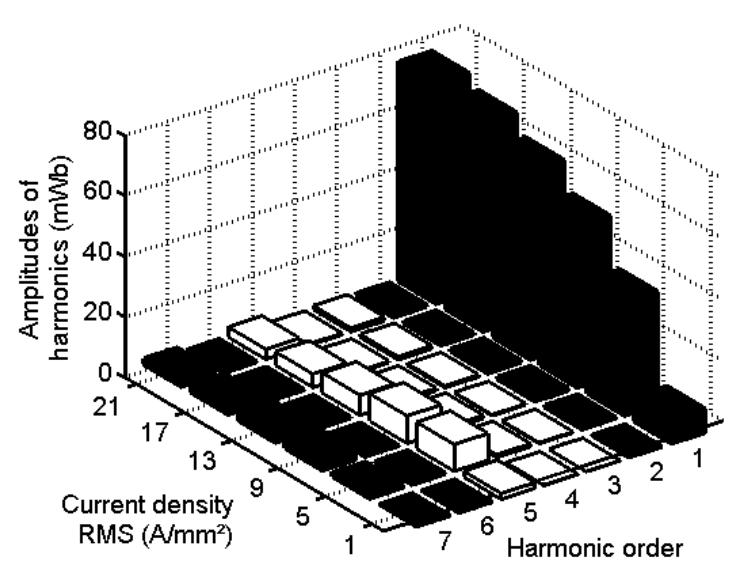

(b)

Fig. 6 Harmonic analysis of one phase flux (phase A) when three phases excited with sinusoidal waveform currents. (a) Classical SRM, (b) MCSRM.

\section{TRAnSIENT Thermal Models (LP AND FEM 2D)}

\section{A. Lumped Parameter Transient Thermal Model}

\section{1) Thermal Conduction}

Since the classical SRM and the MCSRM have the same motor structure, the only difference is the current distribution in stator windings, thus, the heat flux paths should be similar. Furthermore, the heat flux is mainly removed towards the outside of electrical machines in the radial direction, thus, it is safe to study the comparison of temperatures between these two machines in the radial direction. The general expression of temperature $\left(T\left({ }^{\circ} \mathrm{C}\right)\right)$ describing the heat transfer is

$$
-\lambda \nabla^{2} T+\rho c_{p} \frac{\partial T}{\partial t}=\dot{q}
$$

where $\lambda\left(\mathrm{W} / \mathrm{m} /{ }^{\circ} \mathrm{C}\right), \rho\left(\mathrm{kg} / \mathrm{m}^{3}\right), c_{p}\left(\mathrm{~J} / \mathrm{kg} /{ }^{\circ} \mathrm{C}\right)$ and $\dot{q}\left(\mathrm{~W} / \mathrm{m}^{3}\right)$ are thermal conductivity, density, specific heat capacity and heat source, respectively. As in some of previous studies [28]-[29], the stator slots are considered as an equivalent homogeneous material. The equivalent thermal conductivity is obtained by analytical method, and verified by Finite Element and experimental methods. In this paper, an equivalent thermal conductivity of stator windings of $0.84 \mathrm{~W} / \mathrm{m} /{ }^{\circ} \mathrm{C}$ is given for a stator slots filling coefficient of $50 \%$. In order to calculate the thermal resistance in different parts of electrical machines, the identification of limit conditions of the expression Eq. 4 is important. Since the structures of these two machines are cylindrical, thus using two cylinders to represent different parts of machines is possible, which is shown in Fig. 7.

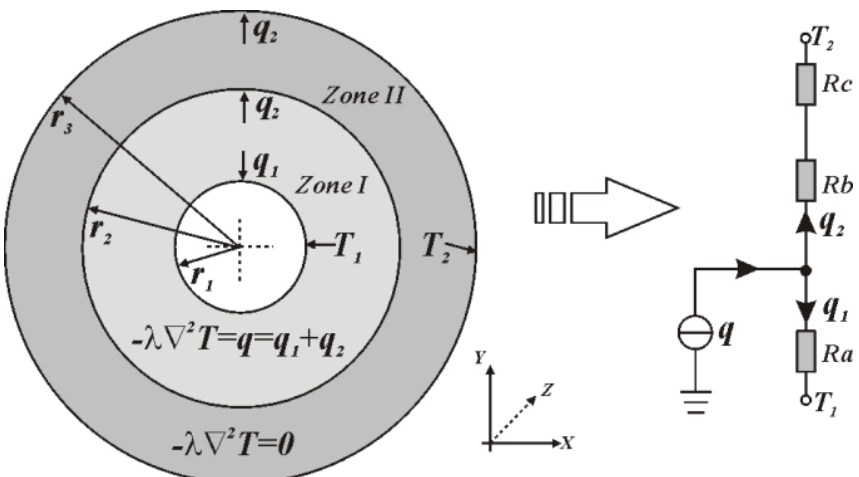

Fig. 7 Zones describing the heat transfer at different parts of electrical machines, Zone I: with heat source $(q \neq 0)$, Zone II: without heat source $(q=0)$.

In the Zone I, the Poisson's equation should be solved, which is the steady-state form of the expression Eq. 4, while in the Zone II, the Laplace's equation should be solved. The Dirichlet conditions are imposed on the inner and outer surfaces, e.g. $T=T_{1}$ and $T=T_{2}$. The length in direction $z$ of the cylinders in question is $L$, and after the resolution of the Poisson and Laplace's equations, the thermal resistances of different parts are obtained as follows:

$$
\left\{\begin{array}{c}
R a=\frac{1}{8 \pi \lambda L}\left(1-\frac{2 r_{1}^{2}}{r_{2}^{2}-r_{1}^{2}} \ln \left(\frac{r_{2}}{r_{1}}\right)\right) \\
R b=R a \\
R c=\frac{1}{2 \pi \lambda L} \ln \left(\frac{r_{3}}{r_{2}}\right)
\end{array}\right.
$$

where $r_{1}(m), r_{2}(m)$ and $r_{3}(m)$ are respectively the inner, the middle and the outer radii of the studied cylinder as in the Fig. 7.

\section{2) Thermal Convection}

In electrical machines, there are two kinds of thermal convection, e.g. between solid surface and ambience (outer convection) as well as between solid surfaces (inner convection). The thermal convection between the outer surface of frame and the ambience is included in the first case, while the thermal convection in the air-gap (between the rotor and the stator), between the end-winding and frame inner lateral surfaces are included in the second case. The foregoing SRMs are designed for a Variable Stator Vane (VSV) application, which participate in the regulation of the aircraft reactor's regime. Thus, the machine should be an enclosed one, and the only cooling system is the ambient air flow nearby the outer surface of the frame (the air pressure nearby the aircraft reactor is high $(P=3$ Bars given in the motor specifications)). After the experimental tests by using a cylinder to replace the SRMs, a convection coefficient between the frame outer surface and ambience $h=30 \mathrm{~W} / \mathrm{m}^{2} /{ }^{\circ} \mathrm{C}$ is given in the machine specifications. Since the machine should be an enclosed one, and there is no motor fan on the shaft in the 
machine, thus, the axial air flow in the air-gap is significantly low and can be ignored in the practical calculation. Furthermore, even if the air flow in the air-gap is turbulent, it could still be considered that there is a thin layer of air nearby the rotor tooth tips, which is laminar, rotates with the rotor with the same peripheral speed. This is the same case for the air flow inter-rotor teeth. The mechanical speed of these machines is relatively low (maximum speed $\Omega_{\max }=7.5 \times$ $10^{3} \mathrm{tr} / \mathrm{min}$ ), thus the rotor slots will not affect considerably the thermal convection and the thermal convection coefficient in air-gap can be calculated as follows [29]-[30]:

$$
T a=\frac{\rho^{2} \Omega^{2} r_{a} e^{3}}{\mu^{2}}
$$

where $\mathrm{Ta}, \Omega(\mathrm{rad} / \mathrm{s}), e(\mathrm{~m}), \mu(\mathrm{Pa} \cdot \mathrm{s})$ and $r_{a}(\mathrm{~m})$ are the Taylor number, the rotor mechanical speed, the air-gap length, the dynamic viscosity of fluid in air-gap and the average value of rotor outer $\left(r_{r_{-} \text {outer }}\right)$ and stator inner $\left(r_{s_{-} \text {inner }}\right)$ radii, which can be calculated from

$$
r_{a}=\frac{e}{\ln \left(\frac{r_{s_{-} \text {inner }}}{r_{r_{-} \text {outer }}}\right)}
$$

For the narrow air-gap, with the measured correlation equations, the Nusselt number for air-gap can be computed as [29], [31]

$$
\begin{cases}N u=2 & (T a<1708) \\ N u=0.128 T a^{0.367} & (1800<T a<12000) \\ N u=0.409 T a^{0.241} & \left(12000<T a<4.10^{6}\right)\end{cases}
$$

Once the Nusselt number in the air-gap is obtained, the thermal convection coefficient $\left(h\left(W \cdot m^{-2} \cdot K^{-1}\right)\right)$ and the thermal resistance $\left(R_{\text {cov }}\right)$ can be calculated as

$$
\begin{gathered}
h=\frac{N u \cdot 2 e}{\lambda} \\
R_{\text {cov }}=\frac{1}{h A}
\end{gathered}
$$

where $A\left(\mathrm{~m}^{2}\right)$ is the exchange surface, $\lambda\left(\mathrm{W} / \mathrm{m} /{ }^{\circ} \mathrm{C}\right)$ is the thermal conductivity.

It should be noted that the precise computation of thermal convection coefficient is a significantly demanding task. This can be performed by lots of Computational Fluid Dynamics (CFD). While the CFD calculations are very time-consuming and need a solid knowledge of mechanical fluid in air-gap, this is certainly a very challenging task in the preliminary conception process of the electrical machines. In the accessible literatures [29], an augmentation of $20 \%$ of surface exchange due to the rotor slots are reported. In this paper, the rotor iron losses are relatively low, and it is safe to use the foregoing method to calculate the thermal convection coefficient. Since the rotor speed is relatively low and the internal thermal convection and thermal conduction are predominant, the thermal radiation is then neglected in this paper [30].

\section{3) Thermal Capacitances}

In order to complete the transient thermal model, the thermal capacitances of different material of electrical machines, which are often used to describe the hysteresis phenomena of temperature variation, should be calculated. The general expression of thermal capacitance $\left(C_{t h}\right)$ is

$$
C_{t h}=c_{p} M=c_{p} V \rho
$$

where $c_{p}\left(\mathrm{~J} / \mathrm{kg} /{ }^{\circ} \mathrm{C}\right), M(\mathrm{~kg})$ and $V\left(\mathrm{~m}^{3}\right)$ are respectively the specific heat capacity, the mass and the volume of material.

After a series of calculations of thermal resistances, thermal capacitances of different motor components, e.g. stator slots, stator teeth, stator yoke, air-gap, rotor teeth and rotor yoke, etc, the complete Lumped Parameter (LP) transient thermal model is finally established such as

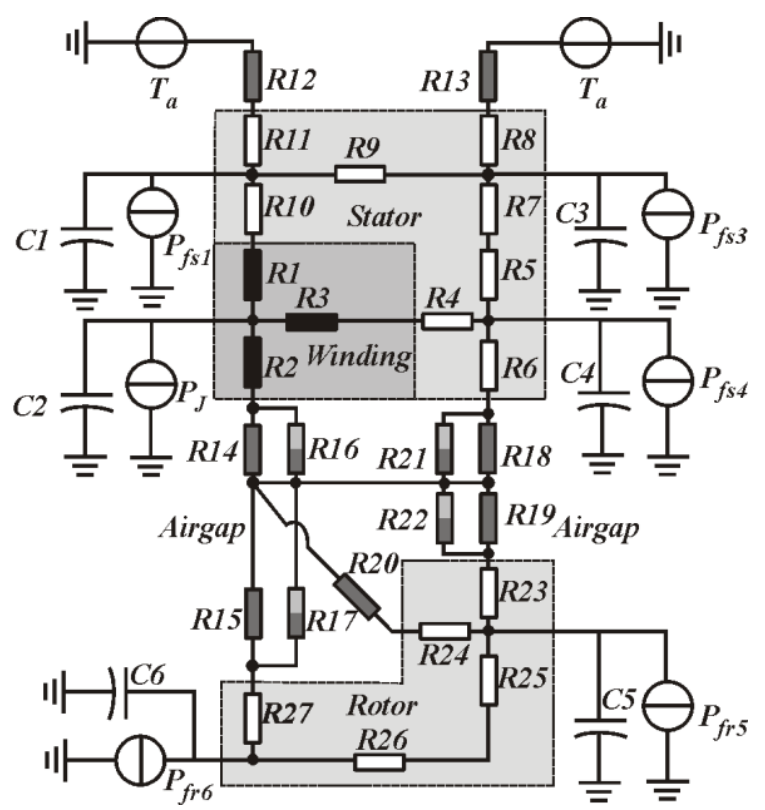

Fig. 8 Lumped parameter transient thermal model of Switched Reluctance Machines (classical SRM and MCSRM).

In this model, the conductive thermal resistances and the convective thermal resistances in air-gap are parallels. The shaft of rotor is not taken into account because there is very little heat flux being removed from the shaft towards the ambient. Moreover, the rotor iron losses are relatively low. After calculating all the thermal resistances and thermal capacitances, the temperature at each node in the LP transient thermal model could be obtained as [32]

$$
[C]_{1 \times n} \frac{d[T]_{n \times 1}}{d t}+[G]_{n \times n}[T]_{n \times 1}=[P]_{n \times 1}
$$

where $[C]_{1 \times n}$ is a column matrix of thermal capacitances, $[G]_{n \times n}$ is a thermal conductance matrix and $[P]_{n \times 1}$ is the power loss matrix.

\section{B. Finite Element (FE) Transient Thermal Model}

As mentioned in previous sections that the two machines are doubly salient, thus, the air flow in the air-gap could be considered as turbulent. Furthermore, the rotor is mobile, the 
velocity of which is variable during one driving cycle as shown in the Fig. 2. This makes the numerical simulation (ANSYS transient thermal 2D) of the SRMs during one driving cycle very difficult, and the thermal model at one rotor position as in steady-state analysis is no longer possible. In this paper, some assumptions have been proposed to obtain an equivalent non-salient rotor and the numerical transient model could be finally established. As we know that the thermal time constant is much longer than the mechanical period of these two machines, thus, the air at the middle of air-gap could have enough time to be heated up uniformly by the rotor tooth tip or the air inter-rotor teeth. As a result, it could be considered that the air at the middle of air-gap is isothermal, and the temperature of which could be the average temperature between the stator inner and the rotor outer radii. Moreover, since there is a fin layer of air nearby the rotor tooth tip rotates with the rotor in the same peripheral velocity, thus, to the immobile part of stator, the rotating rotor part (the mobile rotor and the half of air-gap nearby the rotor) could be considered as an equivalent homogeneous material. In order to obtain the equivalent thermal conductivity of rotor part, the method as in electrical network to simplify the thermal network should be employed to obtain the equivalent thermal resistance. The method is described as follows

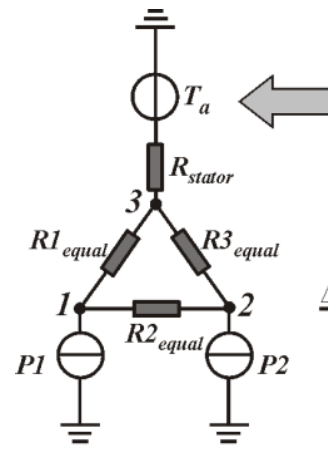

(a)

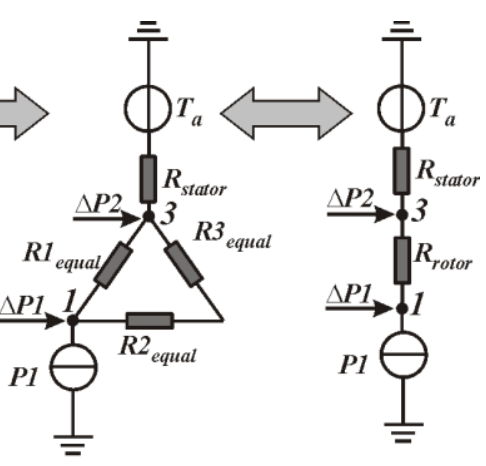

(b) (c)
Fig. 9 Procedure of calculating the equivalent rotor thermal resistance of the classical SRM and the MCSRM.

In the Fig. 9, for simplicity, the stator part is represented by only one thermal resistance $\left(R_{\text {stator }}\right) . T_{a}\left(0^{\circ} \mathrm{C}\right.$ in this paper) is the ambient temperature, $P 1$ and $P 2$ are respectively the iron losses $P_{f r 6}$ and $P_{f r 7}$. The different thermal resistances in the Fig. 9 (a) and (b) are calculated using the network of the Fig. 8 as

$$
\left\{\begin{array}{l}
R 1_{\text {equal }}=R 27+\frac{R 15 \cdot R 17}{R 15+R 17} \\
R 2_{\text {equal }}=R 25+R 26 \\
R 3_{\text {equal }}=\frac{(R 24+R 20)\left(R 23+\frac{R 19 \cdot R 22}{R 19+R 22}\right)}{R 24+R 20+R 23+\frac{R 19 \cdot R 22}{R 19+R 22}}
\end{array}\right.
$$

The equivalent heat source $\Delta P 1$ and $\Delta P 2$ can be calculated as

$$
\left\{\begin{array}{l}
\Delta P 1=R 3_{\text {equal }} \cdot P 2 /\left(R 2_{\text {equal }}+R 3_{\text {equal }}\right) \\
\Delta P 2=R 2_{\text {equal }} \cdot P 2 /\left(R 2_{\text {equal }}+R 3_{\text {equal }}\right)
\end{array}\right.
$$

The rotor part equivalent thermal resistance in the Fig. 9 (c) could be finally obtained as

$$
R_{\text {rotor }}=\frac{\left(R 3_{\text {equal }}+R 2_{\text {equal }}\right) R 1_{\text {equal }}}{\left(R 1_{\text {equal }}+R 2_{\text {equal }}+R 3_{\text {equal }}\right)} \quad \text { Eq. } 15
$$

The shaft and rotor outer radii are kept constant, the equivalent thermal conductivity could then be calculated by the expression Eq. 5. When to the equivalent mass density $\left(\rho_{\text {equal }}\right)$ and equivalent specific heat capacity $\left(c_{p_{-} \text {equal }}\right)$ of rotating rotor part, which can be calculated as follows

$$
\left\{\begin{array}{l}
\rho_{\text {equal }}=\frac{V_{\text {iron }} \cdot \rho_{\text {iron }}}{V_{\text {equal }}} \\
c_{p_{\text {_equal }}}=\frac{V_{\text {iron }} \cdot \rho_{\text {iron }} \cdot c_{p_{\text {_iron }}}}{V_{\text {equal }} \cdot \rho_{\text {equal }}}
\end{array}\right.
$$

Eq. 16

where $V_{\text {iron }}, \rho_{\text {iron }}$ and $c_{p_{-} \text {iron }}$ are respectively the volumes, the mass densities and the specific heat capacities of rotor iron. The mass and thermal capacitance of the air in air-gap are negnected [33].

\section{Analytical and Numerical Results}

With the structural and thermal parameters obtained in previous sections (see annex), the Lumped Parameter and Finite Element models have been performed for the classical SRM and the MCSRM. The analytical and the numerical results of the maximum temperature in stator windings are shown in the Fig. 10 and the Fig. 11. In the Fig. 10, the heat sources are the average copper and iron losses (in this paper, all the mechanical losses are ignored) while in the Fig. 11, the heat sources are the instantaneous values of copper and iron losses. In these two figures, a good agreement between the analytical and the numerical results are observed. At the same time, it is found that either with the average or the instantaneous power losses, the maximum temperature in the stator windings of the classical SRM is significantly higher than that of the MCSRM. This leads that only the MCSRM can satisfy the machine specifications in this paper, because the maximum temperature in the stator windings of the classical SRM is so high that all the insulating materials will be damaged (the temperature has exceeded the temperature limit of $300^{\circ} \mathrm{C}$ ). It is also very important to find when the heat sources are the instantaneous copper and iron losses, the maximum temperature of permanent regime (after 3 driving cycles, the machines enter in the permanent regime) of the MCSRM stator windings $\left(220^{\circ} \mathrm{C}\right)$ is much higher than that $\left(170^{\circ} \mathrm{C}\right)$ of the MCSRM using average copper and iron losses as the heat sources. This is because that the variable copper and iron losses during driving cycles bring temperature ripples, even if the average value is similar to that obtained by average power losses, the maximum value of which could be much higher as shown in Fig. 10 and Fig. 11. Thus, for the machines with driving cycles, the transient thermal model with instantaneous power losses as heat sources is considerably necessary, otherwise, the thermal performances will be significantly overestimated. 


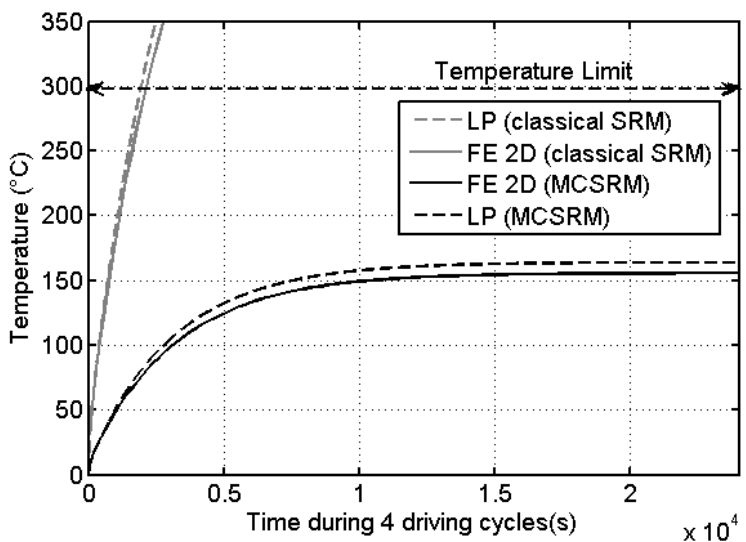

Fig. 10 Variation of maximum temperature in stator windings of classical SRM and MCSRM during 4 driving cycles (heat sources are average iron and copper losses during one driving cycle).

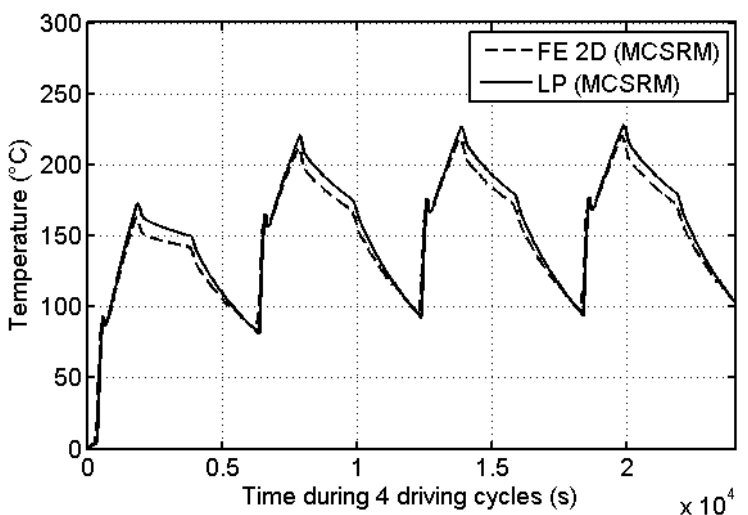

Fig. 11 Variation of maximum temperature in stator windings of MCSRM during 4 driving cycles (heat sources are instantaneous iron and copper losses).

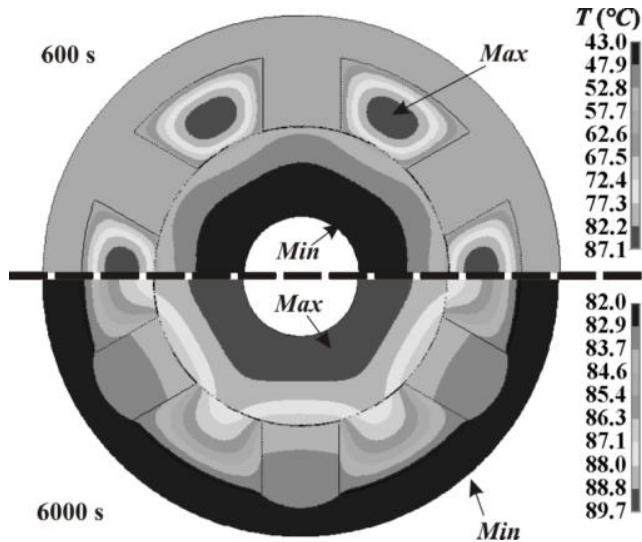

Fig. 12 Temperature distribution of MCSRM at different moments during one driving cycle. Upper half part: at 600 seconds; lower half part: 6000 seconds.

In order to decrease the maximum temperature of the electrical machine, the minimisation of the power losses is always a good choice while enhancing the performance of cooling system is also a good alternative. Several kinds of cooling fins could be applied to increase the heat exchange area on external surface of the frame. To evaluate the heat transfer on a finned surface cooled by air, some methods have been proposed in [34].

Due to the thermal time constant and the variable copper and iron losses during one driving cycle, it is also found that the maximum temperature in the MCSRM could move from the stator windings to the rotor. This is shown as in the Fig. 12 , at 600 second of the driving cycle (upper half part of the Fig. 12), the maximum temperature is at the stator winding, because at this moment, the copper losses in the stator windings are much higher than the iron losses in the stator iron as well as in the rotor iron (see the Fig. 4 and the Fig. 5). While nearby the 6000 second, the rotor iron losses could be higher than copper losses, moreover, the air-gap is not a good thermal conductor. Thus, the rotor temperature can rise relatively higher than the stator winding temperature.

\section{EXPERIMENTAL VERIFICATION}

The machine for experimental tests is a 6-slot, 4-pole SRM (see the Fig. 13), in which the stack length is $61 \mathrm{~mm}$, the stator outer diameter is $63 \mathrm{~mm}$, the rotor outer diameter is $34 \mathrm{~mm}$, the airgap length is $0.4 \mathrm{~mm}$ and the filling factor is 0.3 . The experimentation is realized by a dSPACE-based digital controller, which will drive the classical and MCSRMs, and one DC machine is used as charge of the SRMs. By changing the RMS current density of the SRMs, the output torque of the SRMs is changed. After the experimental tests, the average torque versus RMS current density is obtained, which is shown in the Fig. 14. A good agreement between the simulated and measured results is observed.

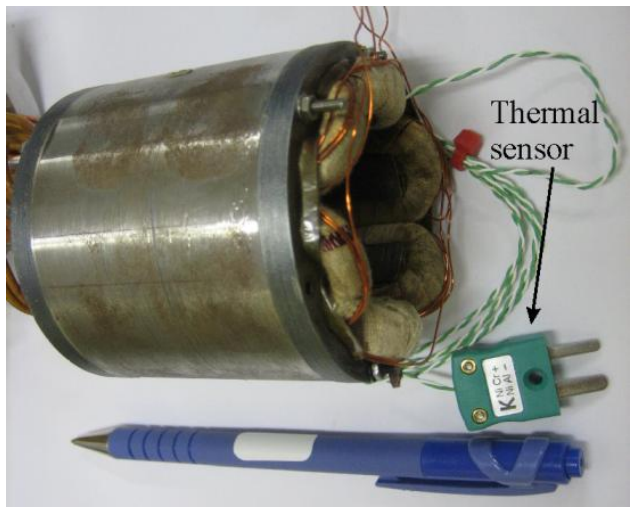

(a)

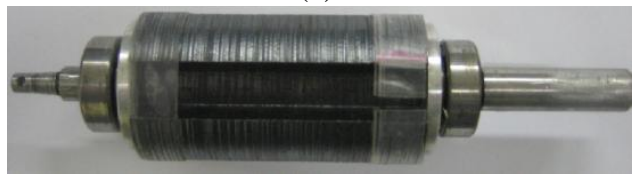

(b)

Fig. 13 SRM 6/4 for thermal and electromagnetic experimental tests. (a) stator, (b) rotor.

In order to measure the temperature versus time, some thermal sensors are respectively implemented in the middle of the stator slots and at the outer surface of stator as shown in the Fig. 13. The convection at the surface of the machine is about $h=25 \mathrm{~W} / \mathrm{m}^{2} /{ }^{\circ} \mathrm{C}$ and the equivalent thermal conductivity is $0.15 \mathrm{~W} / \mathrm{m} /{ }^{\circ} \mathrm{C}$ for a filling factor of 0.3 . As the thermal flux path for these two SRMs is similar, thus, it is sufficient to use the MCSRM for the thermal simulation and the experimentation. The copper loss is $25 \mathrm{~W}$ and the iron losses are about $1.2 \mathrm{~W}$ for a rotor speed of $1000 \mathrm{RPMs}$. In order to verify the two cases as shown in the Fig. 10 and the Fig. 11, where the power losses are respectively constant and instantaneous, we drive the machine so that the copper iron 
losses are constant until 6000 seconds and then, the supply of the machine is turned off and the power losses become null. During this period, the measured temperature versus time is obtained and the results are shown in the Fig. 15. The differences between the measured and simulated results are mainly due to the neglect of the contact thermal conductivity between the machine components, the end effect of endwindings (the machine is relatively short) and roughly estimated thermal convection in airgap between stator and rotor, etc.

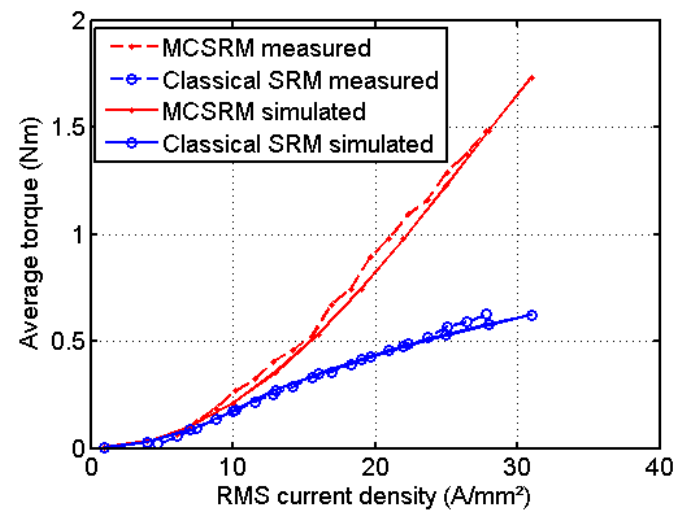

Fig. 14 Results of average torque versus RMS current density, obtained by simulation and experimentation.

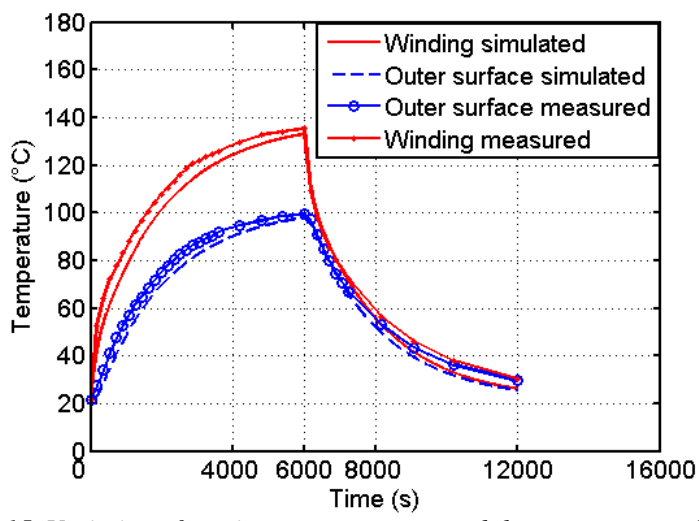

Fig. 15 Variation of maximum temperature and the temperature of stator yoke versus time for the MCSRM obtained by LP model and experimentation.

\section{CONCLUSION}

The instantaneous copper and iron losses models during driving cycle of the classical SRM and the MCSRM have been established. The numerical results have shown that the copper losses of the MCSRM are much lower than those of classical SRM during the same driving cycle. When to the iron losses, because its lower stator flux density harmonics and lower rotor flux density frequency, the MCSRM has lower stator as well as rotor iron losses than those of the classical SRM for the same driving cycle.

The Lumped Parameter transient thermal model has been carried out. In order to validate the analytical model by Finite Element 2D, a transformation of the salient rotor into a non salient one is performed. After a series of calculation, a good agreement between the analytical and numerical results has been observed. Due to its significantly lower copper and iron losses as well as lower maximum stator winding temperature comparing to the classical SRM, only the MCSRM can satisfy the foregoing machine specifications in this paper.

One SRM 6/4 is used for the experimental tests, a good agreement between the simulated and the measured results is observed. It can be conclude that for the electrical machines with driving cycles, the transient thermal model using the instantaneous power losses as heat sources is very important, because the temperature ripple could lead to a much higher maximum temperature than that obtained by steady-state or transient thermal models using the average power losses as heat sources. This should be taken into account in the preliminary conception procedure of electrical machines.

\section{APPENDIX}

STRUCTURAL DATA FOR CLASSICAL SRM AND MCSRM

\begin{tabular}{ll}
\hline Number of stator/rotor poles & $6 / 4 ;$ \\
Stack length & $60 \mathrm{~mm} ;$ \\
Stator outer radius & $45 \mathrm{~mm} ;$ \\
Rotor outer radius & $25.5 \mathrm{~mm} ;$ \\
Air-gap length & $0.2 \mathrm{~mm} ;$ \\
Shaft radius & $10 \mathrm{~mm} ;$ \\
Filling factor & 0.5 \\
\hline
\end{tabular}

THERMAL DATA FOR CLASSICAL SRM AND MCSRM

\begin{tabular}{lccc}
\hline \hline & $\begin{array}{c}\text { Conductivity } \\
\left(\mathrm{W} / \mathrm{m} /{ }^{\circ} \mathrm{C}\right)\end{array}$ & $\begin{array}{c}\text { Density } \\
\left(\mathrm{kg} / \mathrm{m}^{3}\right)\end{array}$ & $\begin{array}{c}\text { specific heat capacity } \\
\left(\mathrm{J} / \mathrm{kg} /{ }^{\circ} \mathrm{C}\right)\end{array}$ \\
\hline \hline Iron & 30 & 8150 & 460 \\
$\begin{array}{l}\text { Equivalent } \\
\text { windings }\end{array}$ & 0.8469 & 6380 & 487.2 \\
Air & 0.03 & 1.23 & 1005 \\
\hline \hline
\end{tabular}

\section{REFERENCES}

[1] J. -W. Ahn, S. -J. Park, and D. -H. Lee, "Hybrid excitation of SRM for reduction of vibration and acoustic noise," IEEE Trans. on Ind. Electron., vol. 51, no. 2, p. 374 - 380, Apr. 2004.

[2] F. C. Lin, S. M. Yang, and J. Lee, "Instantaneous shaft radial force control with sinusoidal excitations for switched reluctance motors," EEE Trans. Energy Convers., vol. 22, p. 629, Sep. 2007.

[3] X. Mininger, N. Galopin, X. Ojeda, F. Bouillault, and M. Gabsi, "Modeling of Magnetoelastic and Piezoelectric Coupling: Application to SRM Noise Damping," IEEE Trans. Magn., vol. 45, no. 3, pp. 12181221, Mar. 2009.

[4] Z. Q. Zhu and D.Howe, "Electrical Machines and Drives for Electric, Hybrid, and Fuel Cell Vehicles," Proc. IEEE, vol. 95, no. 4, pp. 746-765, Apr. 2007.

[5] P. Krishnamurthy, W. Lu, F. Khorrami, and A. Keyhani, "Robust Force Control of an SRM-Based Electromechanical Brake and Experimental Results," IEEE Transaction on Control System Technology, vol. 17, no. 6, pp. 1306-1317, Nov. 2009.

[6] G. J Li, X. Ojeda, E. Hoang, M. Gabsi, and M. Lécrivain, "A New Method of Current Density Distribution for Switching Reluctance Machine to Increase Average output Torque," in PCIM, Shanghai, CHINA, JUNE, 2009.

[7] G. J. Li et al., "Comparative Study of Switched Reluctance Motors Performances for Two Current Distributions and Excitation Modes," in IEEE IECON 2009, Porto, Portugal, Nov. 2009.

[8] B. Fahimi, A. Emadi, and R. B. Sepe, "A switched reluctance machinebased starter/alternator for more-electric cars," IEEE Trans.Energy Convers., vol. 19, no. 1, p. 116-124, Mar. 2004.

[9] M. Krishnamurthy et al., "Making the Case for Applications of Switched Reluctance Motor Technology in Automotive Products," IEEE Tran. 
Power Electron., vol. 21, no. 3, pp. 659-675, May 2006.

[10] T.J.E.Miller, "Optimal design of switched reluctance motors," IEEE Trans. Ind. Electron., vol. 49, no. 1, pp. 15-27, Feb. 2002.

[11] C. Picod, M. Besbes, F. Camus, and M. Gabsi, "Influence of stator geometry upon vibratory behaviour andelectromagnetic performances of switched reluctance motors," in 1997 Eighth International Conference on Electrical Machines and Drives (Conf. Publ. No. 444), 1-3 Sep 1997, pp. 69-73.

[12] S. Ayari, M. Besbes, M. Lecrivain, and M. Gabsi, "Effects of the airgap eccentricity on the SRM vibrations," in Electric Machines and Drives, 1999. International Conference IEMDC '99, May 1999, pp. 138-140.

[13] M. Gabsi, F. Camus, T. Loyau, and J.-L. Barbry, "Noise reduction of switched reluctance machine," in Electric Machines and Drives, 1999. International Conference IEMDC '99, May 1999, pp. 263-265.

[14] C. Pollock and C.-Y. Wu, "Acoustic noise cancellation techniques for switched reluctance drives," IEEE Trans. Ind. Appl., vol. 33, no. 2, p. 477 - 484, Mar./Apr. 1997.

[15] X. Ojeda, X. Mininger, H. Ben Ahmed, M. Gabsi, and M. Lecrivain, "Piezoelectric Actuator Design and Placement for Switched Reluctance Motors Active Damping," IEEE Trans. Energy Convers., vol. 24, no. 2, pp. 305-313, June 2009.

[16] Ahn Jin-Woo, Oh Seok-Gyu, Moon Jae-Won, and Hwang Young-Moon, "A three-phase switched reluctance motor with two-phase excitation," IEEE Trans. Ind. Appl., vol. 35, no. 5, pp. 1067-1075, Sep./Oct. 1999.

[17] J. M. Kokernak and D.A. Torrey, "Magnetic circuit model for the mutually coupled switched-reluctance machine," IEEE Trans. Magn., vol. 36, no. 2, pp. 500-507, Mar 2000.

[18] C. Liu, K. T. Chau, W. Li, and C. Yu, "Efficiency Optimization of a Permanent-Magnet Hybrid Brushless Machine Using DC Field Current Control," IEEE Trans. Magn., vol. 45, no. 10, pp. 4652-4655, Oct. 2009.

[19] J. H. Seo, T. K. Chung, C. G. Lee, S. Y. Jung, and H. K. Jung, "Harmonic Iron Loss Analysis of Electrical Machines for High-Speed Operation Considering Driving Condition," IEEE Trans. Magn., vol. 45, no. 10, pp. 4656-4659, Oct. 2009.

[20] N. Sadowski, M. Lajoie-Mazenc, J. P. A. Bastos, M. V. Ferreira da Luz, and P. Kuo-Peng, "Evaluation and Analysis of Iron Losses in Electrical. Machines Using the Rain-Flow Method," IEEE Trans. Magn., vol. 36, no. 4, pp. 1923-1926, July 2008.

[21] D. M. Ionel et al., "Computation of core losses in electrical machines using improved models for laminated steel," IEEE Trans. Ind. Appl., vol. 43, no. 6, p. 1544-1564, Nov./Dec. 2007.

[22] D. G. Dorrell, "Combined Thermal and Electromagnetic Analysis of Permanent-Magnet and Induction Machines to Aid Calculation," IEEE Trans. Ind. Electron., vol. 55, no. 10, pp. 3566-3574, Oct. 2008.

[23] K. N. Srinivas and R. Arumugam, "Analysis and Characterization of Switched Reluctance Motors: Part II-Flow, Thermal, and Vibration Analyses," IEEE Trans. Magn., vol. 41, no. 4, pp. 1321-1332, Apr. 2005.

[24] L. Alberti and N. Bianchi, "A Coupled Thermal-Electromagnetic Analysis for a Rapid and Accurate Prediction of IM Performance," IEEE Trans. Ind. Electron., vol. 55, no. 10, pp. 3575-3582, Oct. 2008.

[25] M. F. Momen and I. Husain, "Design and Performance Analysis of a Switched Reluctance Motor for Low Duty Cycle Operation," IEEE Trans. Ind. Appl., vol. 41, no. 6, pp. 1612-1618, Sep./Oct. 2005.

[26] S. Inamura, T. Sakai, and K. Sawa, "A Temperature Rise Analysis of Switched Reluctance Motor Due to the Core and Copper Loss by FEM," IEEE Trans. Magn, vol. 39, no. 3, pp. 1554-1557, MAY 2003.

[27] D. Ishak, Z. Q. Zhu, and David Howe, "Eddy-Current Loss in the Rotor Magnets of Permanent-Magnet Brushless Machines Having a Fractional Number of Slots Per Pole," IEEE Trans. Magn., vol. 41, no. 9, pp. 24622469, Sep. 2005.

[28] Ayman M. EL-Refaie, Nathan C. Harris, Thomas M. Jahns, and Khwaja M. Rahman, "Thermal Analysis of Multibarrier Interior PM Synchronous Machine Using Lumped Parameter Model," IEEE Trans. Energy Convers., vol. 19, no. 2, pp. 303-309, June 2004.

[29] J. F. Trigeol, Y. Bertin, and P. Lagonotte, "Thermal Modeling of an Induction Machine Through the Association of Two Numerical Approaches," IEEE Trans. Energy Convers., vol. 21, no. 2, pp. 314-323, June 2006.
[30] J. Nerg, M. Rilla, and J. Pyrhönen, "Thermal Analysis of Radial-Flux Electrical Machines With a High Power Density," IEEE Trans. Ind. Electron., vol. 55, no. 10, pp. 3543-3554, OCT. 2008.

[31] K.-M. Becker and J. Kaye, "Measurement of adiabatic and diabatic fluid flow in an annulus with an inner rotating cylinder," J. Heat Transfer, vol. 84, pp. 97 - 105, 1962.

[32] YG Guo, JG Zhu, and W. Wu, "Thermal Analysis of Soft Magnetic Composite Motors Using a Hybrid Model with Distributed Heat Sources," IEEE Trans. Magn., vol. 41, no. 6, pp. 2124- 2128, 2005.

[33] A. Boglietti et al., "Evolution and Modern Approaches for Thermal Analysis of Electrical Machines," IEEE Trans. Ind. Electron., vol. 56, no. 3, pp. 871-882, Mar. 2009.

[34] M. A. Valenzuela and J. A. Tapia, "Heat transfer and thermal design of finned frames for TEFC variable-speed motors," IEEE Trans. Ind. Electron., vol. 55, no. 10, p. 3500-3508, Oct. 2008.

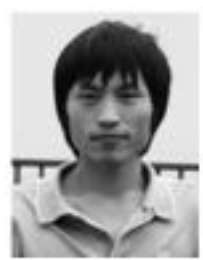

Guangjin LI was born in Xiaogan, China, in 1984. He received his BS and MSc degree in Electrical Engineering from the University of Wuhan, China, in 2007 and Paris XI, Paris, France, in 2008, respectively. $\mathrm{He}$ is currently a Ph.D student in the laboratory SATIE of the Ecole Normale Superieure (ENS) de Cachan, Paris, France. His main research interests include the design and the optimization of the Switched Reluctance Machines and the Flux-Switching Permanent Magnet Machines. The available contact of the author is: guangjin.li@ satie.ens-cachan.fr

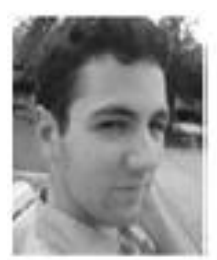

Javier Ojeda was born in 1980 in Buenos Aires, Argentina. He received the $\mathrm{PhD}$ degree in electrical engineering from the Ecole Normale Supérieure de Cachan (ENS Cachan, France) in 2009. He was postdoc at the Tsinghua university (China) in 2010 and he got a position of assistant professor at the ENS Cachan, France in the SATIE Laboratory since September 2010. His main research topics are active damping of SRM motors for high speed applications, machines noise

modeling and fault diagnosis in electrical machines for vehicular applications.

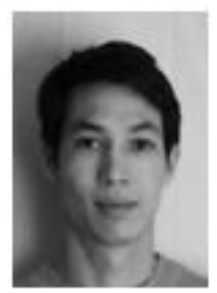

Emmanuel Hoang was born in Antibes, France, in 1966. He receive the "agrégation" in electrical engineering in 1990 and the Ph.D degrees from the Ecole Normale Supérieure de Cachan, in 1995. Since 1990 , he works with the electrical machine team in the SATIE laboratory. His research interests the modelling of the iron losses in SRMs and the design, modelling, optimization and control of novel topologies of PM machines. hoang@satie.ens-cachan.fr

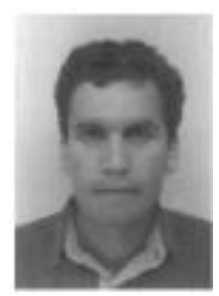

Mohamed Gabsi received his Ph.D degree in electrical engineering from University of Paris-VI in 1987 and his HDR in 1999 from University of Paris-XI (Orsay, France). Since 1990, he is working in electrical machine team (SETE, Systèmes d' 'Energies pour le Transport et l'Environnement) of SATIE laboratory where he is currently a full professor and the director of the electrical engineering department. His research interests include SRM, vibrations and acoustic noise and PM machines.

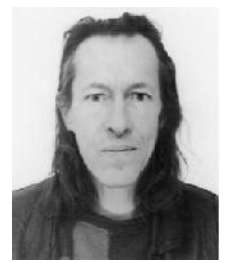

Michel Lécrivain was born in Barneville, France. He received the degree in electrical engineering from the Conservatoire National des Arts et Métiers (CNAM, Paris, France) in 1981. He has joined since 1997, SATIE laboratory as a research engineer. His research interests include the design and control of new hybrid machines and novel permanent magnet machines for automotive applications. 